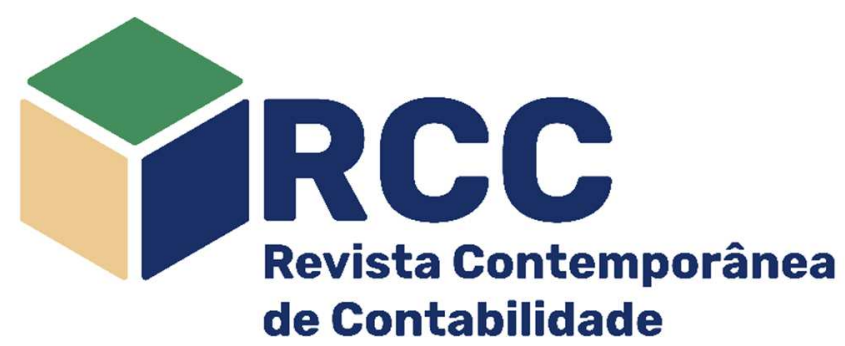

\title{
A adoção das normas internacionais de contabilidade e os investimentos estrangeiros no mercado brasileiro
}

\author{
International Financial Reporting Standards adoption and foreign investments in Brazilian financial \\ market
}

\begin{abstract}
Adopción de normas internacionales de contabilidad e inversiones extranjeras en el mercado brasileño
\end{abstract}

\author{
Edvaldo Dias da Silva Filho \\ Mestre em Ciências Contábeis (FUCAPE) \\ Vitória/ES, Brasil \\ edvaldo2dias@hotmail.com \\ https://orcid.org/0000-0002-4198-6326 (0)
}

Silvania Neris Nossa

Doutora em Ciências Contábeis e Administração (FUCAPE) FUCAPE Business School, Vitória/ES, Brasil

silvanianossa@fucape.br

https://orcid.org/0000-0001-8087-109X (])
Talles Vianna Brugni ${ }^{\star}$ Pós-doutor em Finanças (PUC/Rio) e Doutor em Controladoria e Contabilidade (USP) FUCAPE Business School, Vitória/ES, Brasil tallesbrugni@fucape.br https://orcid.org/0000-0002-9025-9440 (])

Aziz Xavier Beiruth Doutor em Controladoria e Contabilidade pela Faculdade de Economia, Administração e Contabilidade (USP) FUCAPE Business School, Vitória/ES, Brasil aziz@fucape.br https://orcid.org/0000-0001-6962-3044

Endereço do contato principal para correspondência* Avenida Fernando Ferrari, 1358, Boa Vista, CEP 29075-505, Vitória/ES, Brasil

\section{Resumo}

O estudo possui abordagem quantitativa e teve como objetivo analisar os efeitos da adoção das normas internacionais de contabilidade (IFRS) na participação acionária de investidores estrangeiros em empresas brasileiras listadas na Bolsa Brasil Balcão (B3). Foram utilizados dados coletados na base de dados Economática referentes a uma amostra de 362 empresas analisadas no período entre 2005 a 2017 e variáveis macroeconômicas coletadas no site do Banco Mundial, Banco Central do Brasil e Instituto de Pesquisa Econômica Aplicada. Os resultados evidenciam que houve aumento da participação acionária de investidores estrangeiros em empresas brasileiras após a convergência com as normas contábeis internacionais no período de adoção mandatória.

Palavras-chave: IFRS; Value-relevance; Investidor estrangeiro

\begin{abstract}
This study has a quantitative approach and aimed to analyze the International Financial Reporting Standards adoption's effects on foreign investors shareholding on Brazilian companies. Data collected from Economática database were used for a sample of 362 companies analyzed from 2005 to 2017. Macroeconomic variables were collected on the World Bank website, Central Bank of Brazil and Research Institute Applied Economics. The results show that there was an increase in the equity participation of foreign investments in Brazilian companies increased after the convergence with the international accounting standards during the mandatory adoption period.
\end{abstract}

Keywords: IFRS; Value-relevance; Foreign investor

\section{Resumen}

El estudio tiene un enfoque cuantitativo y tuvo como objetivo analizar los efectos de la adopción de las Normas Internacionales de Contabilidad (IFRS) en la participación accionaria de inversionistas extranjeros en empresas brasileñas listadas en la Bolsa de Valores Brasileña (B3). Se utilizaron datos recogidos en la base de datos Economática referentes a una muestra de 362 empresas analizadas en el período desde 2005 hasta 2017 y también variables macroeconómicas recogidas en el sitio del Banco Mundial, Banco Central de Brasil 
e Instituto de Investigación Económica Aplicada. Los resultados evidencian que la participación accionaria de inversionistas extranjeros en las empresas brasileñas se incrementó después de la convergencia con las normas contables internacionales en el período de adopción obligatorio.

Palabras clave: IFRS; Value-relevance; Inversionista extranjero

\section{Introdução}

A adoção das IFRS pode aumentar o investimento estrangeiro nas empresas listadas no Brasil, visto que o padrão internacional já foi adotado em vários países, proporcionando aos investidores internacionais conhecer as IFRS. E neste sentido Márquez-Ramos (2011) destaca que a adoção das IFRS pode reduzir a assimetria de informação ao nível de país ao promover o aumento da transparência. Logo se espera que esse contexto tenha trazido investimento estrangeiro para o mercado acionário brasileiro.

Estudos realizados no Brasil por Silva Filho (2018), Silva Júnior et al. (2016), Santos et al. (2014), Santos e Cavalcante (2014), Gonçalves et al., (2014), Macedo et al. (2013) identificaram um efeito positivo no value relevance das informações contábeis emitidas por empresas brasileiras após a adoção das normas internacionais de contabilidade (IFRS), principalmente após a adoção obrigatória (Silva Filho, 2018; Silva Júnior et al.,2016; Santos et al, 2014; Santos e Cavalcante, 2014; Gonçalves et al., 2014; Macedo et al., 2013). Esse contexto encontrado na literatura mostra que o investidor se mostra mais informado, ou seja, as normas internacionais reduziram a assimetria informacional no mercado acionário brasileiro. E espera-se que essa redução na assimetria informacional seja ainda maior quando se trata de investidor estrangeiro, visto que a norma internacional é conhecida pelos investidores internacionais. E este contexto viabilizaria a entrada de novos investidores estrangeiros no mercado brasileiro.

Deste modo, considerando a importância que as normas internacionais conferem à produção de informações contábeis com qualidade e confiabilidade, visando atender às necessidades dos investidores em um mercado globalizado, este estudo visa responder à seguinte questão: como ocorre a relação da adoção das IFRS e a participação de investidores estrangeiros em empresas brasileiras?

Conforme Amiram (2012), o aumento da utilização do padrão IFRS pode afetar as decisões de investimentos estrangeiros, pois a alta-qualidade das IFRS pode reduzir a assimetria de informação entre investidores locais e estrangeiros. Desta forma, considerando que um padrão uniforme de normas contábeis tem papel fundamental na internacionalização do capital (JOHNSON et al., 2017), o objetivo do estudo é identificar os possíveis efeitos da adoção das IFRS na participação acionária de investidores estrangeiros em empresas brasileiras após a adoção das normas internacionais.

Neste estudo serão desenvolvidos dois testes de hipóteses. O primeiro teste de hipóteses é de que os investimentos estrangeiros em empresas brasileiras listadas na B3 aumentaram após a adoção voluntária das IFRS. E o segundo teste de hipóteses é de que o período após a adoção voluntária das IFRS influencia positivamente o investimento estrangeiro. Note que o período após 2008 coincide com o período em que 0 Brasil adquiriu o grau de investimento da Standard \& Poors e Fitch. O teste das hipóteses será feito tanto no contexto no qual o investidor estrangeiro está entre os cinco maiores acionistas quanto naquele em que o investidor estrangeiro está entre os três maiores acionistas.

Lasmim (2012) argumenta em seu estudo que na medida que países adotam as IFRS podem atrair mais comércio e investimentos internacionais. Apesar dos argumentos neste sentido, há poucas evidências empíricas que os suportem (LASMIN, 2012). E neste sentido, Lourenço e Castelo Branco (2015) concluem em sua pesquisa que o simples compartilhamento de regras não tem poder para criar uma linguagem comum, mas Johnson et al, (2017) afirma que quando se trata de um padrão uniforme para emissão de relatórios financeiros isso pode proporcionar a globalização econômica e com isso se chegar à internacionalização do capital. Desta forma este estudo se justifica na medida em que se faz necessária a análise com dados relacionados à participação estrangeira na estrutura de capital votante das firmas brasileiras, considerando a adoção das normas internacionais de contabilidade. Dessa maneira, busca-se contribuir com a temática já estudada por Amiran (2012) e Figlioli e Lemes (2016), bem como embasar futuras pesquisas relacionadas ao tema no Brasil ou em nível internacional, considerando que as pesquisas que tangenciam o tema observam dados agregados de investimento absoluto, e não a participação acionária como proxy de atratividade das firmas brasileiras perante o investidor institucional estrangeiro.

Como forma de evidenciar os efeitos da harmonização das normas no fluxo de investimentos estrangeiros, aceita-se o resultados de pesquisas anteriores na direção de que há um aumento do value relevance das informações contábeis das companhias brasileiras pós IFRS (Silva Filho, 2018; Júnior et al.,2016; Santos et al., 2014; Santos e Cavalcante, 2014; Gonçalves et al., 2014; Macedo et al., 2013). Esses resultados ajudam na construção da hipótese de que esse aumento de relevância tende a reduzir a assimetria de informação no mercado e, consequentemente, esse contexto pode proporcionar 0 aumento do investimento estrangeiro. Neste sentido, analisou-se os fluxos de capital estrangeiro no Brasil, comparandose o período antes e após adoção das normas internacionais. Para a realização da referida análise, foram utilizados dados dos cinco maiores investidores institucionais obtidos na base de dados Economatica, além de dados macroeconômicos. Os resultados encontrados demonstram que a adoção obrigatória das IFRS exerceu influência significativa sobre a participação de investidores estrangeiros nas empresas contidas na 
amostra. Desta forma, os resultados obtidos encontram-se em consonância com os resultados de estudos como Amiram (2012) e Figlioli e Lemes (2016).

\section{Referencial Teórico}

Neste tópico aborda-se o referencial teórico relativo à adoção das IFRS e as decisões de investimentos pelos investidores. No que se refere à adoção das IFRS, Amiram (2012) defende em seu estudo que ela pode afetar as decisões de investimentos estrangeiros, uma vez que após a adoção das IFRS registrasse melhoria na qualidade da informação e com isso pode-se perceber a redução da assimetria de informação entre investidores locais e estrangeiros. Relatórios financeiros emitidos sob o padrão IFRS refletem melhor as condições individuais e específicas de cada empresa (RUTLEDGE et al., 2015). Neste sentido, Johnson et al. (2017), afirmam que o risco de um investimento envolve a expectativa de perdas no retorno de investimentos e tem papel importante quando a decisão está relacionada à informação financeira emitida sob padrões contábeis diferentes. Eles defendem ainda que um padrão uniforme de normas contábeis tem papel fundamental na internacionalização do capital

Ames (2013) estudou as mudanças na qualidade da informação contábil após a adoção das normas internacionais na África do Sul e encontrou resultados que demonstram que nem todos os componentes dos relatórios financeiros têm melhora na qualidade, caso dos ativos reportados que explicam significativamente menos o preço das ações após a adoção das IFRS. No Mercado Brasileiro nos estudos realizados por Silva Filho (2018), Silva Júnior et al. (2016), Santos et al. (2014), Santos e Cavalcante (2014), Gonçalves et al., (2014), Macedo et al. (2013) esses autores identificaram um efeito positivo no value relevance na medida que as informações contábeis são divulgadas pelas empresas brasileiras após a adoção das normas internacionais de contabilidade (IFRS).

Neste sentido, Silva Filho (2018), Silva Júnior et al. (2016), Santos et al (2014), Santos e Cavalcante (2014), Gonçalves et al. (2014), Macedo et al. (2013) concluíram que a divulgação de informações contábeis impacta mais fortemente o mercado acionário após a adoção obrigatória do IFRS, ou seja, a divulgação voluntária era significativa, mas a divulgação obrigatória se mostra ainda mais forte. Esse contexto encontrado na literatura mostra que o investidor se mostra mais informado após a adoção obrigatória das IFRS. Em outras palavras, as normas internacionais reduzem a assimetria informacional no mercado acionário brasileiro. Neste contexto, espera-se que essa redução na assimetria informacional seja ainda maior quando se trata de investidor estrangeiro, visto que a norma internacional já foi adotada em muitos países estrangeiros ainda em 2005, logo é uma norma já conhecida pelos investidores internacionais. Desta forma a redução da assimetria informacional viabilizaria a entrada de novos investidores estrangeiros no mercado brasileiro após a adoção das IFRS pelas empresas brasileiras.

Os investimentos estrangeiros possuem papel importante na economia de um país. Dados divulgados pela B3 evidenciam que os investimentos estrangeiros estão em constante crescimento na década atual, representando uma média mensal de $44,2 \%$ do volume financeiro negociado no segmento Bovespa, tendo alcançado o patamar de 55,3\% em março de 2016 (Brasil, Bolsa e Balcão, 2018).

$\mathrm{O}$ investimento estrangeiro pode ocorrer de duas maneiras: Investimento Estrangeiro Direto (IED) e Investimento Estrangeiro em Carteira (IEC). Segundo o Banco Central do Brasil (BACEN, 2018), IEC "referese às aplicações estrangeiras em títulos brasileiros, na forma de ações (renda variável) ou títulos de renda fixa (curto e longo prazos), negociados no país ou no exterior". Os IED, conforme Larrañaga et al. (2016), dizem respeito ao investimento de longo prazo envolvendo uma entidade residente em uma economia diferente daquela onde reside o investidor estrangeiro, o qual exerce influência sobre a entidade investida.

Embora o foco deste estudo seja identificar os efeitos da adoção das normas internacionais em investimentos estrangeiros, é importante destacar que os investimentos estrangeiros podem ser explicados por meio de outros fatores que precisam fazer parte do estudo. No Brasil, sabe-se que características macroeconômicas, tais como o aumento da produtividade do trabalho atraem o fluxo de capital estrangeiro (LARRAÑAGA et al., 2016).

No Brasil, bem como em outros países do mundo, o movimento de adoção das IFRS pode ser considerado recente, dado que a maior parte dos países aderiu às normas internacionais na primeira década deste milênio. Este fator, de acordo com Ball (2016), é uma das razões que dificulta a busca por efeitos confiáveis, ocasionando limitações às pesquisas sobre IFRS. Sob este tópico o autor afirma que se deve considerar também que os efeitos da adoção das IFRS possam ser mínimos, a ponto de não ser possível detectá-los.

Lasmim (2012) defende a ideia de que países adotam as IFRS para atrair mais comércio e investimentos internacionais, no entanto, apesar de existirem argumentos fortes e razoáveis neste sentido, há poucas evidências empíricas que os suportem (LASMIN, 2012). Lourenço e Castelo Branco (2015) observam ainda que o simples compartilhamento de regras não tem poder para criar uma linguagem comum. No entanto, um padrão uniforme para emissão de relatórios financeiros é essencial para a globalização econômica e internacionalização do capital (JOHNSON et al., 2017).

Márquez-Ramos (2011) encontrou evidências de benefícios na adoção das IFRS em relação ao comércio de bens e investimentos estrangeiros diretos na Europa. Florou e Pope (2012) investigaram se a 
adoção obrigatória das IFRS gerava aumento na demanda de ações por investidores institucionais e encontraram efeitos positivos entre a adoção das IFRS e o aumento de participações institucionais. Este mesmo efeito foi verificado por Hamberg et al. (2013) em relação à participação acionária de investidores institucionais estrangeiros na Suécia.

A informação apresentada sob padrões contábeis familiares ao investidor facilita seu processamento e a torna mais confiável. Por isso, o custo de processamento de informações apresentadas sob diferentes padrões afeta a demanda do investidor não familiarizado com a informação (YU \&WAHID, 2014). E a assimetria de informação entre investidores locais e estrangeiros, bem como as diferenças existentes nos ambientes de investimentos, estão entre as causas mais comuns que forçam os investidores estrangeiros a focarem seus investimentos no ambiente local em detrimento de investimentos estrangeiros (BALL, 2006; AMIRAM, 2012).

Shroff et al. (2014) estudaram o papel que o ambiente informacional externo tem sobre as decisões de investimentos de empresas multinacionais e concluíram que o ambiente informacional ajuda a mitigar problemas de agência quando as empresas expandem suas operações para o exterior.

Segundo Márquez-Ramos (2011), a assimetria de informação presente nos relatórios financeiros influencia os investimentos estrangeiros, pois afeta a performance das empresas em buscar e investir no exterior. A redução da assimetria de informação promovida pelas IFRS deve resultar em menores custos de processamento de informação, o que levaria ao aumento das entradas de investimento direto estrangeiro (GORDON et al., 2012; CHEN et al., 2014). Em geral, a adoção das IFRS gera efeitos positivos na qualidade da informação, mercado de capitais, capacidade de previsão dos analistas e uso da informação (LOURENÇO; CASTELO BRANCO, 2015). Todo esse contexto viabilizaria a globalização de mercados e com isso o mercado brasileiro poderia receber mais recursos estrangeiros após a adoção das IFRS. Neste sentido, estabelece-se a hipótese de pesquisa:

H1: os investimentos estrangeiros em empresas brasileiras listadas na B3 aumentaram após a adoção obrigatória das IFRS.

H2: os investimentos estrangeiros em empresas brasileiras listadas na B3 aumentaram após a adoção voluntária das IFRS.

O período correspondente à adoção voluntária das IFRS coincide com o período em que o Brasil adquiriu o grau de investimento da Standard \& Poors e Fitch. O teste de $\mathrm{H} 1$ e H2 ocorre tanto no contexto na qual o investidor estrangeiro está entre os cinco maiores acionistas quanto no contexto em que o investidor estrangeiro está entre os três maiores acionistas.

\section{Metodologia}

\subsection{Tipologia, Coleta e Tratamento de Dados}

Trata-se esta pesquisa de um estudo empírico, que se utiliza de dados financeiros das empresas brasileiras listadas. O objetivo desta pesquisa é analisar os efeitos da adoção das normas internacionais de contabilidade (IFRS) na participação acionária de investidores estrangeiros em empresas brasileiras listadas na Bolsa Brasil Balcão (B3). Diante do objetivo da pesquisa, foi realizada uma análise da estrutura societária das referidas empresas durante os anos de 2005 a 2017. O período escolhido para a coleta e análise dos dados justifica-se por estar compreendido entre o período pré-adoção das IFRS no Brasil (2005) e por englobar os anos anteriores à adoção voluntária (2008) bem como os anos posteriores à adoção obrigatória (2010) com vistas a analisar os efeitos da adoção das IFRS na participação acionária de investidores estrangeiros no período antes e após a adoção das IFRS.

Os dados secundários utilizados na pesquisa são provenientes da base de dados Economática e se referem a uma amostra de 362 empresas brasileiras ativas listadas na B3 na data de 27/09/2018 das quais, além de dados contábeis, analisou-se também os cinco maiores proprietários de ações ordinárias com o propósito de identificar, dentre os acionistas, os investidores estrangeiros das respectivas empresas. Neste aspecto, ressalta-se que a presente pesquisa não teve interesse em estratificar a amostra em investidores estrangeiros institucionais e pessoas físicas. Além disso, para efeito de controle, utilizou-se também variáveis macroeconômicas coletadas no site do Banco Mundial, Banco Central do Brasil e Instituto de Pesquisa Econômica Aplicada.

\subsection{Modelo Empírico}

Como forma de analisar os efeitos da adoção das IFRS nos níveis de investimentos estrangeiros no Brasil, este estudo baseia-se nos modelos e variáveis utilizados nos trabalhos de Amiram (2012) e Figlioli e Lemes (2016) os quais observam dados agregados de investimento absoluto, e não a participação acionária como proxy de atratividade das firmas brasileiras perante o investidor institucional estrangeiro, fator que consiste na principal inovação na construção dos modelos apresentados por meio das Equações 1, 2, 3 e 4 utilizados neste estudo. 
estudo:

A seguir apresentam-se as Equações que serão utilizadas para testar a hipótese H1 e H2 deste

$$
\begin{aligned}
& I E 3_{i t}=\alpha_{0}+\alpha_{1} I F R S_{08}+\alpha_{2} \text { TAM }_{i t} \alpha_{3} P_{I B}+\alpha_{4} S E L I C_{t}+\alpha_{5} R_{I S C O B R_{t}}+\varepsilon_{i t} \\
& I E 3_{i t}=\beta_{0}+\beta_{1} I F R S_{10}+\beta_{2} T_{A M} M_{i t}+\beta_{3} P I B_{t}+\beta_{4} S E L I C_{t}+\beta_{5} R I S C O B R_{t}+\varepsilon_{i t} \\
& I E 5_{i t}=\alpha_{0}+\alpha_{1} I_{F R S_{08}}+\alpha_{2} \text { TAM }_{i t} \alpha_{3} P I B_{t}+\alpha_{4} S E L I C_{t}+\alpha_{5} R I S C O B R_{t}+\varepsilon_{i t} \\
& I E 5_{i t}=\beta_{0}+\beta_{1} I F R S_{10}+\beta_{2} T_{A M}+\beta_{3} P_{I B}+\beta_{4} S E L I C_{t}+\beta_{5} R I S C O B R_{t}+\varepsilon_{i t}
\end{aligned}
$$

Em que:

IE3 = participação acionária de investidores estrangeiros entre os três maiores investidores considerando o total do capital da empresa.

IE5 = participação acionária de investidores estrangeiros entre os cinco maiores investidores considerando o total do capital da empresa.

IFRS08 = variável dummy zero, que representa o período anterior e um, que representa o período posterior à adoção voluntária das normas internacionais pelo Brasil.

IFRS10 = variável dummy zero, que representa o período anterior e um que representa o período posterior à adoção obrigatória das normas internacionais pelo Brasil.

$T A M_{i t}=$ representa o logaritmo do ativo total da empresa i constante no $4^{\circ}$ demonstrativo contábil do ano $\mathrm{t}$.

$P I B_{t}=$ representa o logaritmo do produto interno bruto per capta do país em US\$ no ano t.

$S E L I C_{t}=$ representa a taxa média diária de juros Selic over anualizada para o ano t.

$R I S C O B R_{\mathrm{t}}=$ representa o grau de risco do país no ano $\mathrm{t}$ calculado pela metodologia $\mathrm{EMBI}+$.

$\varepsilon i t=$ termo de erro aleatório.

Para fins de definição da variável IFRS, considera-se "adoção voluntária" o período compreendido entre os anos de 2008 e 2009 no qual facultou-se a adoção das normas internacionais para as empresas brasileiras listadas na B3 e "adoção obrigatória" o período após o qual as empresas brasileiras listadas na B3 adotaram obrigatoriamente o padrão contábil internacional (2010).

Nas Equações 1 e 3, a variável que acompanha o coeficiente $\alpha_{1}$, representa o período de adoção voluntária e mandatória juntos com a dummy um para o período posterior a 2008 até 2017 e dummy zero para o período antes de 2008. Desta forma, quando o coeficiente $\alpha_{1}$ apresentar sinal positivo e significante, isso sinaliza que houve aumento na participação acionária de investidores estrangeiros após a adoçao das IFRS, conforme apresentado nos estudos de Amiram (2012) e Fgigioli e Lemes (2016). Ressalta-se que foi no ano de 2008 que o Brasil adquiriu o grau de investimento da Standard \& Poors e Fitch.

Nas equações 2 e 4, a variável que acompanha o coeficiente $\beta_{1}$,representa o período de adoção mandatória com a dummy um para o período posterior a 2010 até 2017 e dummy zero para o período antes de 2010. Desta forma, quando o coeficiente $\beta_{1}$ apresentar sinal positivo e significante, isso sinaliza que houve aumento na participação acionária de investidores estrangeiros após a adoção das IFRS de forma obrigatória. Em relação à variável dummy IFRS ${ }_{10}$, destaca-se que assume valor igual a 0 no período anterior à $2010 \mathrm{e}$ valor igual a 1 após 2010, com o propósito de capturar apenas o efeito da adoção mandatória das IFRS no Brasil.

As variáveis PIB e TAM representam, respectivamente, o logaritmo neperiano do PIB per capta e Ativo Total das empresas, metodologia adotada para corrigir o efeito da variância elevada dos valores apresentados por tais variáveis.

Para controlar o efeito da economia na variância dos níveis de investimento geral em empresas brasileiras, conforme Márquez-Ramos (2011), Lasmin (2012), Amiram (2012), Gordon et al. (2012), Chen et al. (2014), Boateng et al. (2015), Larrañaga et al. (2016) e Figlioli e Lemes (2016), utilizou-se o PIB, a SELIC e o Risco País. O PIB foi coletado no site do Banco Mundial, a Selic no site do Banco Central (BACEN), e para a proxy de "risco país" considerou-se o EMBI+ do Instituto de Pesquisa Econômica Aplica (IPEA).

\section{Resultados e Discussões}

\subsection{Análise da estatística descritiva}

O estudo que investiga a hipótese $\mathrm{H} 1$ envolveu a análise dos três e cinco maiores possuidores de ações ordinárias de cada uma das 362 empresas ativas listadas na B3 ao longo dos anos de 2005 a 2017, das quais também foram obtidos dados contábeis referentes ao ativo total, totalizando 4.133 observações para as variáveis IE3, IE5 e TAM.

Além disso, foram coletados dados referentes à taxa de juros Selic, Produto Interno Bruto (PIB) per capita e risco país nos sites do Banco Central do Brasil (BACEN), Banco Mundial e Instituto de Pesquisa Econômica Aplica (IPEA) respectivamente. A seguir, apresenta-se a estatística descritiva na Tabela 1 para as Equações (1) e (2), e Tabela 2 para as Equações (3) e (4).

A Tabela 1 apresenta a estatística descritiva para os modelos (1) e (2), considerando as variáveis IE3, IFRS, TAM, PIB e RISCOBR winsorizadas a $2 \%$. Ressalta-se que a única diferença entre os modelos 
apresentados consiste na variável IFRS que considera o período anterior e posterior à adoção voluntária das normas internacionais de contabilidade na Equação (1) e o período anterior e posterior à adoção mandatória na Equação (2). Desta forma, as variáveis IE3, TAM, PIB, SELIC e RISCOBR apresentam-se consolidadas dado que representam a mesma amostra nos dois modelos.

Tabela 1 - estatística descritiva das variáveis das equações 1 e 2

$I E 3_{i t}=\alpha_{0}+\alpha_{1} I F R S_{08}+\alpha_{2} T_{A M} M_{i t} \alpha_{3} P I B_{t}+\alpha_{4} S E L I C_{t}+\alpha_{5} R I S C O B R_{t}+\varepsilon_{i t}$

$I E 3_{i t}=\beta_{0}+\beta_{1} I F R S_{10}+\beta_{2} T_{A M}+\beta_{3} P I B_{t}+\beta_{4} S E L I C_{t}+\beta_{5} R I S C O B R_{t+} \varepsilon_{i t}(2)$

\begin{tabular}{l|c|c|c|c|c|c}
\hline \hline \multirow{2}{*}{ Variável } & & Obs & Média & & $\begin{array}{c}\text { Limite } \\
\text { Mínimo }\end{array}$ & $\begin{array}{c}\text { Limite } \\
\text { Máximo }\end{array}$ \\
\hline \hline IE3 & & 4133 & 7,02 & 16,48 & 0,00 & 78,25 \\
\hline \multirow{4}{*}{ IFRS } & $(1)$ & 4133 & 0,80 & 0,40 & 0,00 & 1,00 \\
& $(2)$ & 4133 & 0,66 & 0,48 & 0,00 & 1,00 \\
\cline { 2 - 8 } & & 4133 & 13,85 & 2,81 & 4,23 & 18,91 \\
\cline { 2 - 7 } & & 4133 & 9,14 & 0,27 & 8,47 & 9,48 \\
\cline { 2 - 7 } & & 4133 & 11,34 & 2,87 & 6,90 & 18,00 \\
\cline { 2 - 7 } & & 4133 & 268,13 & 104,02 & 142,00 & 523,00 \\
\hline \hline
\end{tabular}

Nota: Esta tabela apresenta a estatística descritiva da amostra para os modelos (1) e (2).

Fonte: Elaboração própria.

Em relação à variável IE3 o limite mínimo igual a 0 corresponde a períodos nos quais não foram observados investidores estrangeiros entre os 3 maiores sócios das empresas em análise. A Tabela 2 utiliza a mesma metodologia de apresentação das variáveis utilizada na Tabela 1, nela estão representados os dados da estatística descritiva para os modelos (3) e (4) que foram testados para se obter mais robustez nas Equações (1) e (2), considerando as variáveis IE5, IFRS, TAM, PIB e RISCOBR winsorizadas a 2\%. A principal divergência encontra-se na variável IE5 que agrega os investidores estrangeiros entre os 5 maiores sócios das empresas em análise.

Tabela 2- Estatística descritiva das variáveis das equações 3 e 4

$I E 5_{i t}=\alpha_{0}+\alpha_{1} I F R S_{08}+\alpha_{2} T_{A M}{ }_{i t} \alpha_{3} P I B_{t}+\alpha_{4} S E L I C_{t}+\alpha_{5} R I S C O B R_{t}+\varepsilon_{i t}$

$I E 5_{i t}=\beta_{0}+\beta_{1} I F R S_{10}+\beta_{2} T A M_{i t}+\beta_{3} P I B_{t}+\beta_{4} S E L I C_{t}+\beta_{5} R I S C O B R_{t}+\varepsilon_{i t}(4)$

\begin{tabular}{l|c|c|c|c|c|c}
\hline \hline Variável & Modelo & Obs & Média & Desvio Padrão & $\begin{array}{c}\text { Limite } \\
\text { Mínimo }\end{array}$ & $\begin{array}{c}\text { Limite } \\
\text { Máximo }\end{array}$ \\
\hline \hline & & 4.133 & 7,92 & 17,14 & 0,00 & 79,96 \\
\hline \multirow{2}{*}{ IFRS } & $(3)$ & 4.133 & 0,80 & 0,40 & 0,00 & 1,00 \\
& $(4)$ & 4.133 & 0,66 & 0,48 & 0,00 & 1,00 \\
\hline & & 4.133 & 13,85 & 2,81 & 4,23 & 18,91 \\
\cline { 2 - 7 } & & 4.133 & 9,14 & 0,27 & 8,47 & 9,48 \\
\hline
\end{tabular}

Nota: Esta tabela apresenta a estatística descritiva da amostra para os modelos (3) e (4).

Fonte: Elaboração própria.

\subsubsection{Análise da matriz de correlação}

A Tabela 3 evidencia a Correlação de Pearson utilizando as variáveis IE3, IFRS, TAM, PIB e RISCOBR winsorizadas a $2 \%$.

Tabela 3 - Matriz de correlação Pearson das equações 1,2,3, e 4

\begin{tabular}{|c|c|c|c|c|c|c|c|}
\hline & "EQUAÇAO & IE3 & IFRS & TAM & PIB & SELIC & RICOBR \\
\hline IE3 & $\begin{array}{l}(1) \\
(2)\end{array}$ & $\overline{1} 1,0000$ & & & & & \\
\hline IFRS & $\begin{array}{l}(1) \\
(2)\end{array}$ & $\begin{array}{l}0,0507^{\star * *} \\
0,0509^{\star * *}\end{array}$ & 1,0000 & & & & \\
\hline TAM & $\begin{array}{l}\text { (1) } \\
\text { (2) }\end{array}$ & $-0,0605^{\star \star *}$ & $\begin{array}{l}0,1149^{\star \star *} \\
0,1231^{\star * *}\end{array}$ & 1,0000 & & & \\
\hline PIB & $\begin{array}{l}\text { (1) } \\
\text { (2) }\end{array}$ & $0,0446^{\star * *}$ & $\begin{array}{l}0,7997^{\star \star \star} \\
0,7521^{\star \star \star}\end{array}$ & $0,1121^{* \star *}$ & 1,0000 & & \\
\hline SELIC & $\begin{array}{l}(1) \\
(2)\end{array}$ & $-0,0292^{*}$ & $\begin{array}{l}-0,4402^{\star * *} \\
-0,3449^{\star * *}\end{array}$ & $-0,0691^{\star \star *}$ & $-0,6300^{* * *}$ & 1,0000 & \\
\hline RIScORR & (1) & $0,0272^{*}$ & $0,1413^{\star \star \star}$ & 0,0108 & $-0,2411^{* * *}$ & $0,6229^{* * *}$ & \\
\hline KISCUBR & (2) & & $-0,0035$ & & & & \\
\hline
\end{tabular}




\begin{tabular}{|c|c|c|c|c|c|c|c|}
\hline & EQUAÇAO & IE5 & IFRS & TAM & PIB & SELIC & RICOBR \\
\hline \multirow{2}{*}{ IE5 } & (3) & 1,0000 & & & & & \\
\hline & (4) & & & & & & \\
\hline \multirow{2}{*}{ IFRS } & (3) & $0,0575^{\star \star *}$ & 1,0000 & & & & \\
\hline & (4) & $0,0556^{\star \star *}$ & & & & & \\
\hline \multirow{2}{*}{ TAM } & (3) & $-0,0395^{\star *}$ & $0,1149^{\star \star \star *}$ & 1,0000 & & & \\
\hline & (4) & & $0,1231^{\star \star *}$ & & & & \\
\hline \multirow{2}{*}{ PIB } & (3) & 0,0204 & $0,6802^{* * *}$ & $0,1103^{* * *}$ & 1,0000 & & \\
\hline & (4) & & $0,6566^{\star * *}$ & & & & \\
\hline \multirow{2}{*}{ SELIC } & (3) & $-0,0345^{\star *}$ & $-0,4402^{\star \star \star}$ & $-0,0691^{* * *}$ & $-0,4302^{\star * *}$ & 1,0000 & \\
\hline & (4) & & $-0,03449^{\star * *}$ & & & & \\
\hline \multirow{2}{*}{ RISCOBR } & (3) & $0,0274^{*}$ & $0,1413^{\star * *}$ & 0,0108 & $0,0698^{* * *}$ & $0,6229^{* \star *}$ & \\
\hline & (4) & & $-0,0035$ & & & & \\
\hline
\end{tabular}

Nota: Esta tabela apresenta a matriz de correlação da amostra para os modelos (3) e (4). Os símbolos *, ** e ** indicam correlações significantes ao nível de $10 \%, 5 \%$ e $1 \%$ respectivamente.

A análise da Tabela 3 permite identificar uma correlação positiva e significante da variável explicada IE3 e as variáveis IFRS, PIB e RISCOBR, sugerindo preliminarmente que o aumento da participação acionária de investidores estrangeiros pode estar relacionado com o período após adoção das normas internacionais de contabilidade, aumento do PIB brasileiro e aumento do Risco - País. Por outro lado, os resultados da correlação Pearson são univariados, ou seja, não levam em consideração os resultados das variáveis de controle.

Ainda no que se refere à análise univariada da Correlaçao Pearson, em sentido contrário, verifica-se a correlação negativa e significante entre a variável explicada IE3 e as variáveis de controle TAM e SELIC, sugerindo que o aumento percentual da participação de investidores estrangeiro na amostra pode estar associado às empresas com menor ativo total e com a diminuição da taxa de juros no mercado brasileiro (Tabela 3).

Na correlação Pearson para o contexto no qual se observa os investidores entre os cinco maiores investidores, apresentada na Tabela 3 mostra a perda de significância entre a variável IE5 e PIB que nas equações (1) e (2) eram significativas e positivas, sugerindo que, de forma isolada, tomando por base uma amostra maior dos sócios mais relevantes a participação de investidores estrangeiros não possui uma relação direta com o aumento do PIB.

Devido aos níveis elevados de correlação entre as variáveis PIB e IFRS, verificados na Tabela 3, realizou-se o Teste VIF a fim de testar a existência de problemas de multicolinearidade nos quatro modelos apresentados neste estudo. Os resultados demonstraram que não houve indícios de multicolinearidade considerando que todas as variáveis apresentaram $\mathrm{VIF}<10$. Uma vez que os modelos adotados para responder ao problema de pesquisa requer uma análise de dados em painel, a escolha do método a ser utilizado foi definida por intermédio da realização de três testes em conjunto, a fim de verificar quais dos métodos se adequava corretamente aos modelos (1), (2), (3) e (4) sendo o Teste de Chow, Teste de BreuschPagan (LM) e o Teste de Hausman, conforme demonstrado na Tabela 4.

Tabela 4 - Resultado das estatísticas dos testes de especificação dos modelos de regressão

\begin{tabular}{l|l|l|l}
\hline \multirow{2}{*}{ Equação } & Teste de Chow & Teste de Breusch-Pagan LM & Teste de Hausman \\
\cline { 2 - 4 } & Prob>F & Prob>chibar2 & Prob>chi2 \\
\hline $\mathbf{( 1 )}$ & 0,0000 & 0,0000 & 0,0089 \\
\hline $\mathbf{( 2 )}$ & 0,0000 & 0,0000 & 0,0062 \\
\hline $\mathbf{( 3 )}$ & 0,0000 & 0,0000 & 0,0000 \\
\hline $\mathbf{4})$ & 0,0000 & 0,0000 & 0,0000 \\
\hline
\end{tabular}

Fonte: Elaboração própria.

Conforme se verifica na Tabela 4, por meio do Teste de Chow e Teste de Breush-Pagan, rejeitou-se a utilização do Modelo de Regressão Pooled. Diante disso, foi realizado o Teste de Hausman aumentado, cujo resultados indicam a utilização do Modelo de Regressão com Efeitos Aleatórios para todos os modelos.

$\mathrm{Na}$ Tabela 5 a seguir apresenta-se os resultados da regressão dos dados em painel com efeito aleatório para os Equações (1) e (2) com o objetivo analisar os efeitos da adoção das normas internacionais de contabilidade (IFRS) na participação acionária de investidores estrangeiros em empresas brasileiras listadas na Bolsa Brasil Balcão (B3). 
Tabela 5 - Resultados da regressão em painel com efeito aleatório

\begin{tabular}{|c|c|c|c|c|c|c|c|}
\hline \multicolumn{8}{|c|}{$\begin{array}{l}I E 3_{i t}=\alpha_{0}+\alpha_{1} I F R S_{08}+\alpha_{2} T_{A M} M_{i t} \alpha_{3} P I B_{t}+\alpha_{4} S E L I C_{t}+\alpha_{5} R I S C O B R_{t+} \varepsilon_{i t} \\
I E 3_{i t}=\beta_{0}+\beta_{1} I F R S_{10}+\beta_{2} T_{1} M_{i t}+\beta_{3} P I B_{t}+\beta_{4} S E L I C_{t}+\beta_{5} R I S C O B R_{t}+\varepsilon_{i t}(2)\end{array}$} \\
\hline IE3 & Modelo & Coeficiente & Erro Padrão & $\mathbf{z}$ & $P>|z|$ & [95\% Interv & de Confiança] \\
\hline \multirow{2}{*}{ IFRS } & (1) & $-1,318787$ & 0,7821129 & $-1,69$ & 0,092 & $-2,8517$ & 0,2141264 \\
\hline & (2) & $1,404593^{\star \star \star}$ & 0,4914023 & 2,86 & 0,004 & 0,4414626 & 2,367724 \\
\hline \multirow{2}{*}{ TAM } & (1) & $-0,1207069$ & 0,1612958 & $-0,75$ & 0,454 & $-0,4368409$ & 0,1954271 \\
\hline & (2) & $-0,216728$ & 0,1635786 & $-1,32$ & 0,185 & $-0,5373363$ & 0,1038802 \\
\hline \multirow{2}{*}{ PIB } & (1) & $1,933891^{*}$ & 1,090399 & 1,77 & 0,076 & $-0,2032516$ & 4,071033 \\
\hline & (2) & $-1,432548$ & 0,990223 & $-1,45$ & 0,148 & $-3,373351$ & 0,508254 \\
\hline \multirow{2}{*}{ SELIC } & (1) & $-0,2906402^{* * *}$ & 0,0878163 & $-3,31$ & 0,001 & $-0,462757$ & $-0,1185233$ \\
\hline & (2) & $-0,2713137^{\star * *}$ & 0,0832612 & $-3,26$ & 0,001 & $-0,4345028$ & $-0,1081247$ \\
\hline \multirow{2}{*}{ RISCOBR } & (1) & $0,0113621^{* * *}$ & 0,0023503 & 4,83 & 0,000 & 0,0067556 & 0,0159686 \\
\hline & (2) & $0,0082581^{* * *}$ & 0,0018564 & 4,45 & 0,000 & 0,0046196 & 0,0118965 \\
\hline \multirow{2}{*}{ Constante } & (1) & $-7,527998$ & 9,89858 & $-0,76$ & 0,447 & $-26,92886$ & 11,87286 \\
\hline & $(2)$ & $23,17282^{\star *}$ & 9,519384 & 2,43 & 0,015 & 4,515168 & 41,83047 \\
\hline
\end{tabular}

Nota: Esta tabela apresenta os resultados da regressão em painel com efeito aleatório para os modelos (1) e (2). Os símbolos ${ }^{*},{ }^{* *} \mathrm{e}^{* * *}$ indicam correlações significantes ao nível de $10 \%, 5 \%$ e $1 \%$ respectivamente.

Fonte: Elaboração própria.

Os valores obtidos na Tabela 5 indicam uma relação negativa e significante, entre as variáveis IE3 e IFRS para o modelo (1), no entanto o p-valor apresentado não é significante ao nível de $5 \%$ de maneira possibilite afirmar que exista associação entre as variáveis. De modo oposto, a relação entre as variáveis IE3 e IFRS torna-se positiva e significante para o modelo (02). Diante disso, pode-se afirmar que a adoção obrigatória das normas internacionais de contabilidade influenciou positivamente os investimentos estrangeiros nas empresas brasileiras listadas na B3. Destaca-se que os resultados encontrados estão alinhados com estudos como o de Figlioli e Lemes (2016), cujo estudo demonstrou existir associação entre a convergência integral das IFRS e os níveis de investimentos direto estrangeiro no Brasil de modo que o investidor estrangeiro esteja entre os três maiores acionistas. Estes resultados estão alinhados àqueles encontrados por Amiram (2012) entre a adoção das IFRS e os investimentos estrangeiros em carteira em diversos países.

A análise da relação entre a variável TAM e IE3 demonstra não haver existência de uma relação significativa em nenhum dos modelos propostos. Desta forma, não é possível afirmar que exista associação entre a participação acionária de investidores estrangeiros e o tamanho das empresas brasileiras. (Tabela 5)

A variável PIB apresenta coeficiente positivo e significante para o modelo (1), indicando que o aumento do PIB per capita influencia positivamente no nível de investimentos estrangeiros por meio da participação acionária nas empresas brasileiros, embora o p-valor apresentando não possibilite afirmar a existência dessa associação (Tabela 5).

De modo oposto, a relação entre PIB e IE3 no modelo (2) não é significativa. Uma possível explicação para isso, é o fato de que o modelo considera três proxies macroeconômicas com comunalidades relevantes. Diante disso, uma parte do efeito do PIB pode estar nas variáveis SELIC e RISCO.

A variável SELIC mostrou-se estatisticamente significante com a variável IE3 tanto para o modelo (1) quanto para o modelo (2), sendo tal relação de natureza negativa. Tal fato implica dizer que os investimentos estrangeiros em empresas listadas na B3 aumentam à medida que a taxa básica de juros brasileira (Selic) diminui. Pode-se explicar a relação entre as duas variáveis pela possível atratividade dos investimentos estrangeiros em renda fixa quando a taxa básica de juros aumenta (Tabela 5).

Por fim, analisa-se a relação entre as variáveis IE3 e RISCOBR, a qual apresentou-se significante e positiva em ambos os modelos. Isto significa que, independente da adoção voluntária ou obrigatória das IFRS, o investidor estrangeiro demonstra ter perfil moderado a arrojado para investimentos em renda variável (Tabela 5).

Para fornecer maior robustez aos resultados obtidos pela regressão dos modelos (1) e (2), foram rodados os modelos (3) e (4) analisando os cinco maiores acionistas de cada empresa nos períodos após adoção voluntária e adoção obrigatória das IFRS. Os resultados são apresentados na Tabela 06.

Os resultados obtidos estão em linha com os modelos (3) e (4), ou seja, é possível verificar o efeito significativo e positivo da adoção as normas internacionais de contabilidade na participação acionária de investidores estrangeiros entre os cinco maiores investidores em empresas brasileiras por meio do modelo (4). Destaca-se que os resultados encontrados só se mostram significativos quando se observa a adoção das IFRS de forma mandatória, ou seja, após 2010. Estes resultados também confirmam os achados de Amiram (2012) entre a adoção das IFRS e os investimentos estrangeiros (Tabela 6). 
Tabela 6 - Resultados da regressão em painel com efeito aleatório

\begin{tabular}{|c|c|c|c|c|c|c|c|}
\hline \multicolumn{8}{|c|}{$\begin{array}{l}I E 5_{i t}=\alpha_{0}+\alpha_{1} I F R S_{08}+\alpha_{2} T_{A M} M_{i t} \alpha_{3} P I B_{t}+\alpha_{4} S E L I C_{t}+\alpha_{5} R I S C O B R_{t+} \varepsilon_{i t} \\
I E 5_{i t}=\beta_{0}+\beta_{1} I F R S_{10}+\beta_{2} T A M_{i t}+\beta_{3} P I B_{t}+\beta_{4} S E L I C_{t}+\beta_{5} R I S C O B R_{t+} \varepsilon_{i t}(4)\end{array}$} \\
\hline IE5 & Modelo & Coeficiente & Erro Padrão & $\mathbf{z}$ & $P>|z|$ & [95\% Interv. & Confiança] \\
\hline \multirow{2}{*}{ IFRS } & (3) & $-0,8174316$ & 0,5990373 & $-1,36$ & 0,172 & $-1,991523$ & 0,35666 \\
\hline & (4) & $0,7856335^{*}$ & 0,4411729 & 1,78 & 0,075 & $-0,0790495$ & 1,650317 \\
\hline \multirow{2}{*}{ TAM } & (3) & $-0,0089837$ & 0,16628 & $-0,05$ & 0,957 & $-0,3348865$ & 0,3169191 \\
\hline & (4) & $-0,1042878$ & 0,1696459 & $-0,61$ & 0,539 & $-0,4367577$ & 0,2282421 \\
\hline \multirow{2}{*}{ PIB } & (3) & $1,827609^{\star \star}$ & 0,8255196 & 2,21 & 0,027 & 0,2096199 & 3,445597 \\
\hline & (4) & 0,4487501 & 0,878941 & 0,51 & 0,610 & $-1,273943$ & 2,171443 \\
\hline \multirow{2}{*}{ SELIC } & (3) & $-0,2824623^{\star \star *}$ & 0,094812 & $-2,98$ & 0,003 & $-0,4682905$ & $-0,0966341$ \\
\hline & (4) & $-0,2274748^{* * *}$ & 0,0856798 & $-2,65$ & 0,008 & $-0,395404$ & $-0,0595455$ \\
\hline \multirow{2}{*}{ RISCOBR } & (3) & $0,0095494^{\star \star \star}$ & 0,0023228 & 4,11 & 0,000 & 0,0049968 & 0,0141019 \\
\hline & (4) & $0,0084698^{* * *}$ & 0,0021239 & 3,99 & 0,000 & 0,0043069 & 0,0126326 \\
\hline \multirow{2}{*}{ Constante } & (3) & $-7,237989$ & 7,738832 & $-0,94$ & 0,350 & $-22,40582$ & 7,929843 \\
\hline & (4) & 5,180262 & 8,470995 & 0,61 & 0,541 & $-11,42258$ & 21,78311 \\
\hline
\end{tabular}

Nota: Esta tabela apresenta os resultados da regressão em painel com efeito fixo para os modelos (3) e (4). Os símbolos ${ }^{*},{ }^{* *} e^{* * *}$ indicam correlações significantes ao nível de $10 \%, 5 \%$ e $1 \%$ respectivamente.

Fonte: Elaboração própria.

A variável PIB manteve-se não significante no modelo (4) considerando apenas o período de adoção mandatória das IFRS. De modo oposto, essa relação é positiva e significante no modelo (3) estando em linha com Chen et al. (2014) o qual afirma que o investimento estrangeiro direito aumenta com o aumento do PIB per capita (Tabela 6).

As variáveis SELIC e RISCOBR mantiveram sua significância e direção de sinal em ambos os modelos, reforçando a hipótese de que uma parte do efeito do PIB pode estar sendo capturado pelas variáveis SELIC e RISCO BR (Tabela 6).

Portanto, tomando-se uma amostra maior dos sócios mais relevantes, verifica-se que os efeitos das normas internacionais sobre os investimentos estrangeiros permaneceram inalterados na amostra, bem como os efeitos das variáveis de controle SELIC e RISCOBR (Tabela 6).

Tanto na Tabela 5 quanto na Tabela 6 mostra-se o resultado no qual se olha para a variável IFRS 08 das Equações 1 e 3, que é um teste importante por se tratar do período no qual o Brasil adquiriu o grau de investimento pela Standard \& Poors e Fitch e adotou voluntariamente as IFRS. E o fato de o resultado não ser significativo também é um resultado importante, pois traz a informação de que o grau de investimento junto com a adoção das IFRS de forma voluntária não são significativos para trazer investimentos estrangeiros. Mas quando se olha para o beta de IFRS ${ }_{10}$, verifica-se que a adoção da IFRS de forma obrigatória é significativa e positiva, ou seja, a adoção do IFRS de forma obrigatória aumenta o investimento estrangeiro no mercado brasileiro tanto no contexto em que o investidor estrangeiro está entre os três maiores acionistas quanto no contexto em que o investidor estrangeiro está entre os cinco maiores acionistas.

\section{Considerações Finais}

O estudo teve como objetivo analisar os efeitos da adoção das normas internacionais de contabilidade (IFRS) na participação acionária de investidores estrangeiros em empresas brasileiras listadas na Bolsa Brasil Balcão (B3). Os resultados contribuem para ratificar os estudos de Figlioli e Lemes (2016) e Amiram (2012) que encontraram relação positiva entre a adoção das IFRS e os investimentos estrangeiros diretos e investimentos estrangeiros em carteira respectivamente.

Outro resultado importante é aquele de que o período no qual o Brasil adquiriu o grau de investimento pela Standard \& Poors e Fitch e adotou voluntariamente as IFRS não se mostrou significativo junto com a adoção das IFRS de forma voluntária para trazer investimentos estrangeiros. E este resultado se manteve quanto olha-se para o contexto no qual o investidor estrangeiro está entre os três maiores acionistas e entre os cinco maiores acionistas.

Desta forma, pode-se afirmar que a hipótese $\mathrm{H} 1$ desta pesquisa não foi rejeitada, sinalizando que o nível de participação de investidores estrangeiros aumentou após o período de adoção obrigatória das normas internacionais de contabilidade (IFRS).

No que se refere a $\mathrm{H} 2$, essa hipótese foi rejeitada. Os resultados desta pesquisa também contribuem para a literatura de value relevance, uma vez que demonstra a utilidade da informação contábil para os investidores estrangeiro na avaliação de empresas e, consequentemente nas suas decisões de investimentos. 
Em resumo, considerando que a informação contábil é relevante para os investidores, pode-se afirmar que os investimentos estrangeiros no mercado acionário brasileiro aumentaram após a adoção mandatória das normas internacionais de contabilidade, mas somente após a adoção das IFRS de forma obrigatória.

Por fim, destaca-se que a principal limitação da pesquisa realizada está relacionada à amostra utilizada, a qual restringiu-se ao estudo de ações ordinárias. Desta forma, em relação à estudos futuros, sugere-se a análise específica de outros ativos negociados na bolsa de valores brasileira bem como de outros mercados acionários.

\section{Referências}

AMES, Daniel. IFRS adoption and accounting quality: The case of South Africa. Journal of Applied Economics and Business Research, v. 3, p. 154-165, 2013. Doi: doi.org/10.1080/20421338.2018.1478482

AMIRAM, Dan. Financial Information Globalization and Foreign Investment Decisions. Journal of International Accounting Research, v. 11, n. 2, p. 57-81, 2012. Doi:10.2308/jiar-50282. 2012

BALL, Ray. International financial reporting standards (IFRS): pros and cons for investors. Accounting and Business Research. v. 36 (Supplement 1), p. 5-27, 2006. doi.org/10.1080/00014788.2006.9730040

BALL, Ray. Why We Do International Accounting Research. Journal of International Accounting Research, v. 15, n. 2, summer 2016. doi.org/10.2308/jiar-51403

BANCO CENTRAL DO BRASIL. Disponível em: http://www4.bcb.gov.br/pec/series/port/metadados/mg182p.htm. Acesso em: 03 mar. 2017.

BANCO CENTRAL DO BRASIL. Disponível em: https://www.bcb.gov.br/pt-br/\#!/c/COPOMJUROS/\#notas. Acesso em: 17 out. 2018.

BOATENG, Agyenim; HUA, Xiuping; NISAR, Shaista; WU, Junjie. Examining the determinants of inward FDI: Evidence from Norway. Economic Modelling, v. 47, p. 118-127, 2015.

doi.org/10.1016/j.econmod.2015.02.018

BRASIL BOLSA BALCÃO. Relação com Investidores. Disponível em: http://ri.bmfbovespa.com.br/. Acesso em: 20 jul. 2018.

CHEN, Charles J.P.; DING, Yuan; XU, Bin. Convergence of accounting standards and foreign direct investment. The International Journal of Accounting, v. 49, n. 1, p. 53-86, 2014.

doi.org/10.1016/j.intacc.2014.01.007

COMITÊ DE PRONUNCIAMENTOS CONTÁBEIS (CPC). CPC 00 - Estrutura Conceitual para Elaboração e Divulgação de Relatório Contábil-Financeiro, 2011. Disponível em:

http://static.cpc.mediagroup.com.br/Documentos/147_CPC00_R1.pdf. Acesso em: 01 mar. 2017.

FIGLIOLI, Bruno; LEMES, Sirlei. Efeito da adoção das IFRS no Brasil no nível de investimentos diretos estrangeiros. In: X Congresso ANPCONT, 4, p. 1-17, 2016. Anais..., 2016.

FLOROU, Annita; POPE, Peter F. Mandatory IFRS Adoption and Institutional Investment Decisions. The Accounting Review, v. 87, n. 6, p. 1993-2025, 2012.

GORDON, Lawrence A.; LOEB, Martin P.; ZHU, Wenjie. The impact of IFRS adoption on foreign direct investment. Journal of Accounting and Public Policy, v. 31, p. 374-398, 2012. Doi:

10.1016/j.jaccpubpol.2012.06.001

GOLÇALVES, João C; BATISTA, Breno L. L; MACEDO, Marcelo A. S; MARQUES, José A. V. C. Análise do impacto do processo de convergência às normas Internacionais de contabilidade no Brasil: um estudo com base na Relevância da informação contábil. Revista Universo Contábil, v. 10, n.3, p. 25-43, 2014. Doi: doi.org/10.2307/2490232

HAMBERG, Mattias; MAVRUK, Taylan; SJÖGREN, Stefan. Investment allocation decisions, home bias and the mandatory IFRS adoption. Journal of International Money and Finance, v. 36, p. 107-130, 2013. DOI: 10.1016/j.jimonfin.2013.04.001 
JOHNSON, Gary G; WU, Zheng; VARNON, Anthony. Investment decision risk analysis: preliminary evidence of the impact of accounting rules' convergence. International Journal of Business, Accounting, and Finance, v. 11, n. 2, 2017.

LARRAÑAGA, Félix A; HILDEBRAND E GRISI, Celso C. de; MONTINI, Alexandra de A. Fatores competitivos que afetam a decisão de investimento direto estrangeiro no Brasil. RAM, Revista de Administração Mackenzie, v. 17, n. 1, p. 112-134, 2016.

INSTITUTO DE PESQUISA ECONÔMICA APLICADA. Disponível em:

http://www.ipeadata.gov.br/ExibeSerie.aspx?module=M\&serid=40940. Acesso em: 17 out. 2018.

LASMIN, Damian. The Unwanted Effects of International Financial Reporting Standards (IFRS) Adoption on International Trade and Investments in Developing Countries. Journal of Economics and Economic Education Research, v. 13, n. 1, 2012.

LOURENÇO, Isabel M. E. C.; CASTELO BRANCO, Manuel E. M. de A. D. Main Consequences of IFRS Adoption: Analysis of Existing Literature and Suggestions for Further Research. Revista Contabilidade \& Finanças - USP, v. 26, n. 68, p. 126-139, mai./jun./jul./ago. 2015.

MACEDO, Marcelo A. S, MACHADO, Márcio A. V, MACHADO, Márcia R. Análise da relevância da informação contábil no Brasil num contexto de convergência às normas internacionais de contabilidade. Revista Universo Contábil, v. 9, n.1, p. 65-85, 2013. http://dx.doi.org/10.4270/ruc.20139

MÁRQUEZ-RAMOS, Laura. European Accounting Harmonization: Consequences of IFRS Adoption on Trade in Goods and Foreign Direct Investments. Emerging Markets Finance \& Trade, v. 47, n. 4, p. 42-57, 2011.

RUTLEDGE, Robert W.; KARIM, Khondkar E.; GONG, Jia. Convergence of PRC GAAP with IFRS, and the Comparative Value Relevance between the Two Sets of Reporting Standards: The Case of Dual-Listed Chinese Companies. Journal of Accounting and Finance, v. 15, n. 4, p. 165, 2015.

SANTOS, Mateus A. C; CAVALCANTE, Paulo R. N. O Efeito da Adoção dos IFRS sobre a Relevância Informacional do Lucro Contábil no Brasil. Revista Contabilidade \& Finanças - USP, v. 25, n. 66, p. 228241, 2014. DOI: 10.1590/1808-057x201410690

SANTOS, Alexandre Corrêa; STAROSKY FILHO, Loriberto; KLANN, Roberto Carlos. Efeitos do processo de convergência às normas internacionais de contabilidade no value relevance das demonstrações contábeis de organizações brasileiras. Revista Contemporânea de Contabilidade. v. 11, n. 22, p. 95-118, abr. 2014. doi.org/10.5007/2175-8069.

SILVA FILHO, E. D. Adoção das normas internacionais de contabilidade e os investimentos estrangeiros no mercado brasileiro. Dissertação (Mestrado em Contabilidade) - FUCAPE Business School. Vitória, 2018.

SILVA JUNIOR, Júlio C. A.; CALDEIRA, João F.; TORRENT, Hudson da S. O Impacto das IFRS na qualidade da informação contábil no Brasil: o uso de grupos de controle construídos por pareamento do escore de propensão. In: ENCONTRO BRASILEIRO DE FINANÇAS, 16., 2016, Rio de Janeiro. Anais..., SBFin, 2016.

SHROFF, Nemit; VERDI, Rodrigo S.; YU, Gwen. Information Environment and the Investment Decisions of Multinational Corporations. The Accounting Review, v. 89, n. 2, p. 779-790, 2014.

THE WORLD BANK. Disponível em: https://data.worldbank.org/country/brazil?locale=pt. Acesso em: 17 out. 2018.

YU, Gwen; WAHID, Ainda Sijamic. Accounting Standards and International Portfolio Holdings. The Accounting Review, v. 89, n. 5, p. 1895-1930, 2014.

\section{NOTAS}

\section{AGRADECIMENTOS}

Agradecemos a Michigan State University, pois essa ideia surgiu lá durante um Seminário de pesquisa do programa de Doutorado Sanduiche proporcionado por Joseph Anthony a Silvania N. Nossa. Agradecemos 
também à FUCAPE Business School, CAPES e FAPES pelo apoio e estrutura proporcionados aos pesquisadores.

\section{CONTRIBUIÇÃO DE AUTORIA}

Concepção e elaboração do manuscrito: S. N, Nossa, E. D. Silva Filho, T. V. Brugni

Coleta de dados: S. N, Nossa. E. D. Silva Filho

Análise de dados: S. N, Nossa. E. D. Silva Filho, T. V. Brugni

Discussão dos resultados: S. N, Nossa. E. D. Silva Filho, T. V. Brugni, A. X.Beiruth

Revisão e aprovação: S. N, Nossa, T. V. Brugni, A. X.Beiruth

\section{CONJUNTO DE DADOS DE PESQUISA}

O conjunto de dados que dá suporte aos resultados deste estudo não está disponível publicamente.

\section{FINANCIAMENTO}

O presente trabalho foi realizado com apoio da Coordenação de Aperfeiçoamento de Pessoal de Nível Superior - Brasil (CAPES) - Código de Financiamento 001 (Bolsa de Doutorado Sanduiche) e Projeto de pesquisa com o apoio da FAPES sobre investidores institucionais.

\section{CONSENTIMENTO DE USO DE IMAGEM}

Não se aplica.

\section{APROVAÇÃO DE COMITÊ DE ÉTICA EM PESQUISA}

Não se aplica.

\section{CONFLITO DE INTERESSES}

Não se aplica.

\section{LICENÇA DE USO}

Os Direitos Autorais para artigos publicados neste periódico são do autor, com direitos de primeira publicação para a Revista. Em virtude de aparecerem nesta Revista de acesso público, os artigos são de uso gratuito, com atribuições próprias, em aplicações educacionais, de exercício profissional e para gestão pública. A Revista adotou a licença Creative Commons Atribuição 4.0 Internacional - CC BY NC ND. Esta licença permite acessar, baixar (download), copiar, imprimir, compartilhar, reutilizar e distribuir os artigos desde que com a citação da fonte, atribuindo os devidos créditos de autoria. Nesses casos, nenhuma permissão é necessária por parte dos autores ou dos editores. Autores têm autorização para assumir contratos adicionais separadamente, para distribuição não-exclusiva da versão do trabalho publicada nesta revista (ex.: publicar em repositório institucional ou um capítulo de livro).

\section{PUBLISHER}

Universidade Federal de Santa Catarina. Curso de Ciências Contábeis e Programa de Pós-graduação em Contabilidade. Publicação no Portal de Periódicos UFSC. As ideias expressadas neste artigo são de responsabilidade de seus autores, não representando, necessariamente, a opinião dos editores ou da universidade.

\section{EDITORES}

Carlos Eduardo Facin Lavarda e Suliani Rover

\section{HISTÓRICO}

Recebido em: 27/09/2019 - Revisado por pares em: 22/05/2020 - Reformulado em: 16/06/2020 Recomendado para publicação em: 10/07/2020 - Publicado em: 30/07/2020 